\title{
Smart Electric Meter Notification System Using Iot
}

\author{
Vaishnavi $\mathrm{M}^{\mathrm{a}, 1}$ and valarmathi $\mathrm{K}^{\mathrm{b}}$ \\ ${ }^{a} P G$ scholar, Dept of CSE, Panimalar Engineering college, chennai \\ ${ }^{\mathrm{b}}$ Professor, Dept of CSE, Panimalar Engineering college, chennai
}

\begin{abstract}
Electricity is the basic needs of our life and one cannot think of a world without electricity. In the existing meter reading technology, the meter reading process is done by the help of labor force. But this methodology is subjected to many disadvantages like errors throughout calculation, absence of consumer throughout billing time and additional expenses for the billing method. Existing work aims to reduce the labor force for the billing. An energy measurement through wireless smart meter using IoT is proposed for automatic meter data collection, gives announcement through messages displayed on LCD and energy auditing. To overcome this problem IoT based smart electric meter is developed as proposed project.
\end{abstract}

Keywords.IoT, smart meter, electricity

\section{Introduction}

IoT of physical items gadgets, vehicles, structures and elective things installed with material science, programming, sensors, and system property that permit these articles to assemble and trade data. It's provided with particular identifiers and in this manner the capacity to move data over a system while not expecting human-to-human or human-to-PC collaboration. The trap of Things (IoT) has the office to shift our reality. Furthermore, while we will in general square measure getting down to see its incomprehensible effect; we will in general square measure still significantly at necessities to connect every single potential article to act each other on the web to supply secure, comfort life for human. Web of Things (IoT) makes our reality as feasible as associated along. The snare of Things (IoT), is plot in light of the fact that the system the beginning of the transformational venture. Here's a look into the current situation inside the race to institutionalize IoT, related to what people square measure discourse concerning it. The natural impediment of this structure is that astounding needs to go division by zone and he needs to investigate the meter of each house and handover the EB work environment. Blunders like additional bill aggregate or feeling from the board work environment square measure Steady screws up. To crush this weight, the anticipated idea is sent and designed it out. To make an impact charge, a circuit prepared laborer goes to the house on more than one event in every month take the readings from the imperativeness meter. The contemplating is refreshed inside the

\footnotetext{
${ }^{1}$ Vaishnavi M, PG scholar, Dept of CSE, panimalar engineering college, Chennai; Email:vaishnavim2010@gmail.com
} 
work to supply a bill. This issue is vanquished in focal point of 2000. Here EB individual should get back home and take the examininginvigorates in EB working environment. (Regular system) This issue crushes by electric meter the client's EB unit is refreshed to the server normally using reasonable meter.

\section{Related Works}

Mustafa Burunkaya, Tufan Pars, et al in [1] proposes that there is a increasing demands on electricity so there should be a replacement of effective smart grid applicationZigBee,STM32 Nucleo-64 board are the technology used for smart meter design and the disadvantage is that The PC is not cost efficient. It has been concluded that Wireless Sensor Home Area Network (WSHAN) with ZigBee combined smart meter was designed, implemented and tested. Visalatchi S, and Kamal Sandeep K [2] in their work have addressed downside of Power larceny management wherever Energy larceny may be a quite common problem in countries like Asian nation wherever shoppers of energy area unit increasing systematically because the population will increase and that we have used Adriano, GSM to beat this downside and at last it's been terminated that This method can scale back the labor work and human error within the distribution system and additionally defend the buyerinstrumentality. Sook-Chin Yipet al [3] addressed the idea of Electricity felony with LR- ETDM algorithmic program, CVLR-ETDM algorithmic program, Two-tailed p-value Approach this method simply show the quantity of felony however there's no privacy it's been all over that we've designed associate degreed made an AMI take a look at rig to gaugethe performance of the planned linearregression-based energy felony detection algorithms in sensible gridsetting. Dr.P.Mathiyalagan, Ms.A.Shanmugapriya [5] created economical energy conservation policies should be enforced so as to scale back residential electricity consumption victimization $\mathrm{R}$ and Hadoop. It's been terminated that The streaming information is loaded into HDFS in a veryhive table, that is additional exported into Rso as to perform prophetic analysis and cargo profileanalysis.Yang Jincheng, Jiang Ping, et al [6] uses the technology ofC5.0 algorithmic program with good meter failure happens thus it ought to be known and also the limitation is merely halfdozen attributes that will have an effect on the good meters were elect to investigate during this paper it's been finished that Results from example verification indicate that accuracy of failure prediction model for good meters supported C5.0 algorithmic program. 


\section{Proposed Smart Electric Meter}

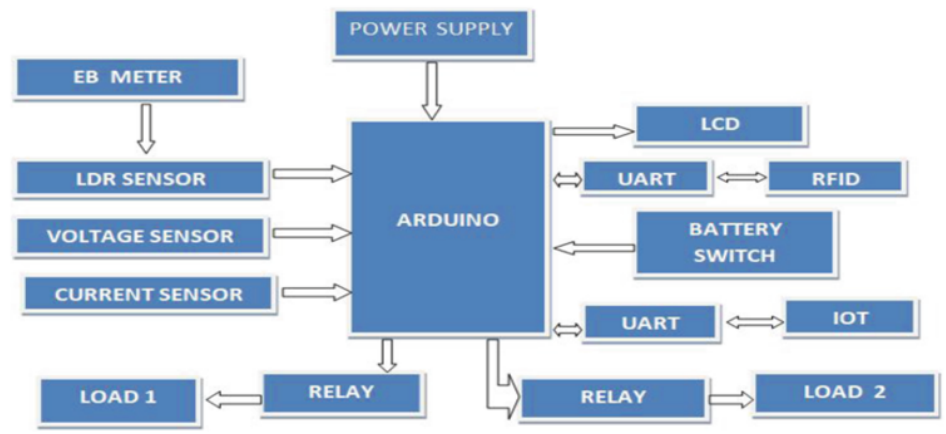

Figure1. Proposed smart electric meter

\subsection{Electric Meter Reading}

IOT based smart electric meter is made and it hopes to diminish the work for the charging. A vitality check through remote snappy meter utilizing IOT is made arrangements for altered meter information accumulation, give proposal through messages showed up on LCD and essentialness assessing, the buyer's EB unit examining and cost will be exchanged to the server therefore and sees the consistently EB unit age and cost. It can give critical information, for instance, charge assortment and due date for the portion. The client can pay through online with the RFID tag.

\subsection{Atmega 328 Microcontroller Connected with Sensors}

EB meter is connected with the LDR sensor. It senses the photochemical energy, it converts photochemical energy into electrical energy. Arduino Uno is a microcontroller board used in smart meter system and it is connected with the following sensors are LDR, voltage and current sensor. The current and voltage readings of the load area unit measured is based on the current and voltage sensor within the analog measuring and is given to the microcontroller for the facility consumption units calculation. This power calculation is performed by programming it within the Arduino package (IDE)

\section{Hardware Aspects}

\subsection{Current Sensor}

A stream identifying part may be a contraption that distinguishes electrical miracle in the midst of a wire, and delivers a proof relative thereto stream. The created banner might be basic voltage or current or maybe an automated yield. 


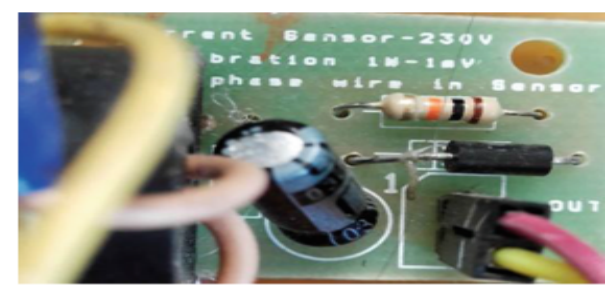

Figure 2. Current sensor

\subsection{Voltage Sensor}

The Voltage Sensor square watches out for an ideal voltage sensor, that is a contraption that changes over voltage assessed between two of an electrical circuit into a physical banner appearing differently in relation to the voltage.

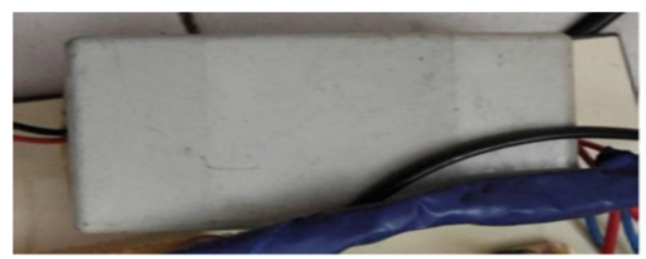

Figure 3. Voltage sensor

\subsection{Electric Tripper}

Some shaped case circuit breakers, particularly bigger breakers, can be physically stumbled by squeezing the "PUSH TO TRIP" button on the substance of the electrical switch. At the point when the catch is squeezed the tripper bar pivots up and to one side.

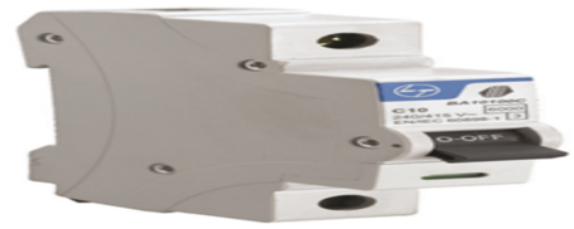

Figure 4. Electric Meter

\section{Result and Discussion}

The smart electric meter displays the power consumption, voltage and current and it also updated to the EB server automatically. The user knows the power consumption units and cost in the daily basis. 


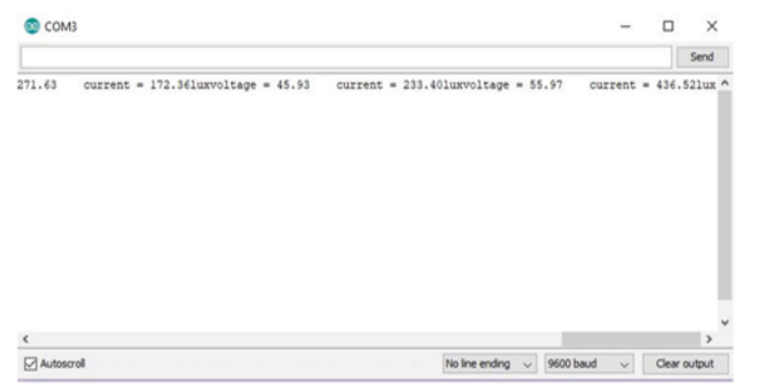

Figure 5. smart electric meter connected to LCD

\section{Conclusion}

Right now have proposed another plan for brilliant electric meter. In Traditional technique labor is required to take current bill utilization, to insinuate the client about the present utilization charges. Our administration is utilizing an advanced meter to compute the bill status of the client. In the wake of finishing the bill cycle no one but client can ready to get the bill in light of the fact that, there is no insinuation for the client until the finish of two months. In the proposed work, the customer's EB unit perusing and cost will be transferred to the server naturally without the need of EB individual's information. In the wake of noticing the perusing the customer can pay through on the web, this application assists with seeing the day by day EB unit age and cost. Power charge cycle will be diminished to one month. Also, the framework will be upgraded by executing on the web cash installment framework; notwithstanding that if the EB bill isn't paid by the customer for the specific arrangement of days then the force supply to that specific house was detached naturally by utilizing RFID Tag lastly we utilize a warning framework by controlling off any of the profoundly power expending gadget when the unit arrives at the steady worth.

\section{References}

[1] M. Burunkaya and T. Pars, A smart meter design and implementation using zigbee based wireless sensor network in smart grid in 2017 4th International Conference on Electrical and Electronic Engineering (ICEEE). IEEE, 2017, pp. 158-162.

[2] A. S. Metering, S. Visalatchi, and K. K. Sandeep, Smart energy metering and power theft control using arduino\&gsm .in 2017 2nd International Conference for Convergence in Technology (I2CT). IEEE, 2017, pp. 858-961.

[3] S.-C. Yip, C.-K. Tan, W.-N. Tan, M.-T. Gan, and A.-H. A. Bakar, Energy theft and defective meters detection in ami using linear regression in 2017 IEEE International Conference on Environment and Electrical Engineering and 2017 IEEE Industrial and Commercial Power Systems Europe (EEEIC/I\&CPS Europe). IEEE, 2017, pp. 1-6.

[4] Vidhya, R and Valarmathi, K, Automatic Monitoring of Hydroponics System Using IoT.in 2019 International Conference on Emerging Current Trends in Computing and Expert Technology. IEEE,2019,PP. 641--648.

[5] Y. Jincheng, J. Ping, C. Guangyu, Y. Tiejiang, and X. Fei, Application of c5. 0 algorithm in failure prediction of smart meters .in 2016 13th International Computer Conference on Wavelet Active Media Technology and Information Processing (ICCWAMTIP). IEEE, 2016, pp. 328-333.

[6] P. Mathiyalagan, A.Shanmugapriya, and A. Geethu, Smart meter data analytics using $r$ and hadoop.in 2017 IEEE International Conference on Electro Information Technology (EIT). IEEE, 2017, pp. 623629 . 